\title{
A Loss-Minimization DTC Scheme for EV Induction Motors
}

\author{
Abdelhakim Haddoun, Mohamed El Hachemi Benbouzid, Senior Member, IEEE, \\ Demba Diallo, Senior Member, IEEE, Rachid Abdessemed, Jamel Ghouili, and Kamel Srairi
}

\begin{abstract}
This paper proposes a strategy to minimize the losses of an induction motor propelling an electric vehicle (EV). The proposed control strategy, which is based on a direct flux and torque control scheme, utilizes the stator flux as a control variable, and the flux level is selected in accordance with the torque demand of the EV to achieve the efficiency-optimized drive performance. Moreover, among EV's motor electric propulsion features, the energy efficiency is a basic characteristic that is influenced by vehicle dynamics and system architecture. For this reason, the EV dynamics are taken into account. Simulation tests have been carried out on a $1.1-\mathrm{kW}$ EV induction motor drive to evaluate the consistency and the performance of the proposed control approach.
\end{abstract}

Index Terms-Direct torque control (DTC), electric vehicle (EV), induction motor, loss minimization.

\section{INTRODUCTION}

A S SHOWN in [1], an electric vehicle (EV) drive system must feature the following:

- high instant power and high power density;

- high torque at low speeds for starting and climbing, as well as high power at high speed for cruising;

- very wide speed range including constant-torque and constant-power regions;

- fast torque response;

- high efficiency over wide speed and torque ranges;

- high efficiency for regenerative braking;

- high reliability and robustness for various vehicleoperating conditions;

- reasonable cost.

The shortcomings, which caused the EV to lose its early competitive edge, have yet to be totally overcome. Indeed,

Manuscript received June 23, 2005; revised February 8, 2006, February 22, 2006, and March 4, 2006. The review of this paper was coordinated by Prof. A. Emadi.

A. Haddoun is with the University of Oum El Bouaghi, Oum El Bouaghi 04000, Algeria.

M. E. H. Benbouzid is with the Laboratoire d'Ingénierie Mécanique et Electrique (LIME), Electrical Engineering Department, IUT of Brest, University of Western Brittany, 29231 Brest Cedex 3, France (e-mail: m.benbouzid@ieee.org).

D. Diallo is with the Laboratoire de Génie Electrique de Paris (LGEP), CNRS UMR 8507, University Paris Sud, Supélec, University Paris VI, 91192 Gif-Sur-Yvette, France (e-mail: ddiallo@ieee.org).

R. Abdessemed is with the University of Batna, Batna 05000, Algeria.

J. Ghouili is with the Groupe de Recherche en Electrotechnologie (GRET), Faculty of Engineering, University of Moncton, Moncton, NB E1A 3E9, Canada.

K. Srairi is with the University of Biskra, Biskra 07000, Algeria.

Color versions of one or more of the figures in this paper are available online at http://ieeexplore.ieee.org.

Digital Object Identifier 10.1109/TVT.2006.889562
EVs have low energy density and long charging time for the present batteries. Therefore, optimal energy management is very important in EVs; in addition, optimum design of the motor, selection of a proper drive, and optimal control strategy are the other major factors in EVs.

For EV propulsion, the cage induction motor seems to be a candidate that better fulfills the aforementioned major features [2]. Induction motor drive control techniques are well treated in the literature. The most popular is the so-called vector control technique that is now used for high-impact automotive applications [EV and hybrid EV (HEV)]. In this case, the torque control is extended to transient states and allows better dynamic performances [1], [3]. Among these techniques, direct torque control (DTC) appears to be very convenient for EV applications [4]-[7]. DTC has the advantage of not requiring speed or position encoders and uses voltage and current measurements only. Flux, torque, and speed are estimated. It also has a faster dynamic response due to the absence of the proportionalintegral (PI) current controller. The input of the motor controller is the reference speed, which is directly applied by the pedal of the vehicle.

Furthermore, the typical advantages of DTC are not sufficient. EV induction motor drive has also to possess high efficiency in order to extend the running distance per battery charge. Therefore, DTC should be associated to a lossminimization strategy to maximize the drive efficiency. Indeed, $\mathrm{EV}$ motors have a high torque-to-volume ratio and a wide speed operation range [8]. Consequently, these motors are characterized by their low inductance and high current density, so that they run at high speed and produce a high starting torque. Due to the low-inductance coil design, the current ripple caused by pulsewidth modulation switching makes a significant amount of eddy current losses and hysteresis losses, especially in highspeed operation. If we simply neglect the iron losses, then it detunes the overall vector controller and results in an error in the torque control [9]. Loss minimization in the induction motor is directly related to the choice of the flux level. The higher the flux level is, the larger the iron losses are. However, extreme minimization causes high copper losses. There is an optimal flux level that guarantees loss minimization. Choosing the level of flux in the induction motor remains an open problem from the perspective of maximizing motor efficiency, and many researchers continue to work on this problem. Numerous operation schemes have been proposed by many researchers concerning the optimal choice of excitation current or flux level for a given operating point. In low-frequency operation, core loss (hysteresis and eddy current loss) is rather low compared with 
copper loss. As the speed goes up, however, the contribution of the eddy current loss increases and finally becomes dominant. Hence, the optimal combination of $d$-axis and $q$-axis currents varies depending on the required torque and speed [10].

Among the aforementioned motor drive features, the energy efficiency is a basic characteristic that is influenced by vehicle dynamics and system architecture. Therefore, in this paper, a detailed dynamic model of an EV is introduced and associated with the proposed loss-minimizing DTC induction motor drive strategy. The objective here is to test the effectiveness of the proposed efficiency optimization strategy on the whole vehicle and not on the sole induction motor. Simulation tests have been carried out on a $1.1-\mathrm{kW}$ EV induction motor drive to evaluate the consistency and the performance of the proposed optimization approach.

\section{Vehicle Dynamics Analysis}

\section{A. Nomenclature}

$v \quad$ Vehicle speed.

$\alpha \quad$ Grade angle.

$P_{v} \quad$ Vehicle driving power.

$F_{w} \quad$ Road load.

$F_{\text {ro }} \quad$ Rolling resistance force.

$F_{\text {sf }} \quad$ Stokes' force or viscous friction force.

$F_{\text {ad }} \quad$ Aerodynamic drag force.

$F_{\text {cr }} \quad$ Climbing and downgrade resistance force.

$\mu \quad$ Tire rolling resistance coefficient $(0.015<\mu<0.3)$.

$m$ Vehicle mass.

$g \quad$ Gravitational acceleration constant.

$k_{A} \quad$ Stokes' coefficient.

$\xi \quad$ Air density.

$C_{w} \quad$ Aerodynamic drag coefficient $\left(0.2<C_{w}<0.4\right)$.

$A_{f} \quad$ Vehicle frontal area.

$v_{0} \quad$ Headwind velocity.

$F \quad$ Tractive force.

$k_{m} \quad$ Rotational inertia coefficient $\left(1.08<k_{m}<1.1\right)$.

a Vehicle acceleration.

$J \quad$ Total inertia (rotor and load).

$\omega_{m} \quad$ Motor mechanical speed.

$T_{B} \quad$ Load torque accounting for friction and windage.

$T_{L} \quad$ Load torque.

$T_{m} \quad$ Motor torque.

$i \quad$ Transmission ratio.

$\eta_{t} \quad$ Transmission efficiency.

$R \quad$ Wheel radius.

$J_{V} \quad$ Shaft inertia moment.

$J_{W} \quad$ Wheel inertia moment.

$\lambda \quad$ Wheel slip.

\section{B. Dynamics Analysis}

Based on the principles of vehicle mechanics and aerodynamics, one can assess both the driving power and energy necessary to ensure vehicle operation (Fig. 1) [8], [11], [12].

1) Road Load and Tractive Force: The road load consists of

$$
F_{w}=F_{\text {ro }}+F_{\text {sf }}+F_{\text {ad }}+F_{\text {cr }} .
$$

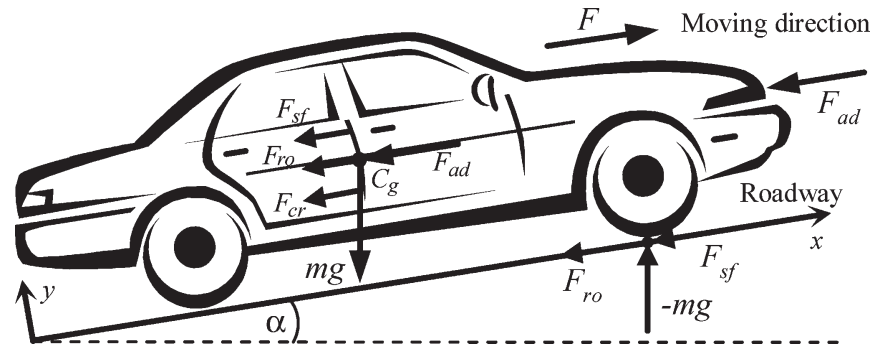

Fig. 1. Elementary forces acting on a vehicle.

The rolling resistance force $F_{\text {ro }}$ is produced by the tire flattening at the roadway contact surface, i.e.,

$$
F_{\text {ro }}=\mu m g \cos \alpha
$$

where $\mu$ is nonlinearly dependent of the vehicle speed, tire pressure and type, and road surface characteristic. It increases with vehicle speed as well as during vehicle turning maneuvers. The rolling resistance force can be minimized by keeping the tires as much inflated as possible, i.e.,

$$
F_{\mathrm{sf}}=k_{A} v .
$$

This force is generally neglected according to the rolling resistance [12]. Aerodynamic drag $F_{\text {ad }}$ is the viscous resistance of air acting upon the vehicle, i.e.,

$$
F_{\text {ad }}=\frac{1}{2} \xi C_{w} A_{f}\left(v+v_{0}\right)^{2} .
$$

The climbing resistance ( $F_{\text {cr }}$ with positive operational sign) and the downgrade force ( $F_{\text {cr }}$ with negative operational sign) are given by

$$
F_{\text {cr }}= \pm m g \sin \alpha .
$$

The tractive force in an EV is supplied by the electric motor in overcoming the road load. The equation of motion is given by

$$
k_{m} m \frac{d v}{d t}=F-F_{w} .
$$

The net force $\left(F-F_{w}\right)$ accelerates the vehicle (or decelerates when $F_{w}$ exceeds $F$ ).

2) Motor Ratings and Transmission: The power required to drive a vehicle has to compensate the road load $F_{w}$, i.e.,

$$
P_{v}=v F_{w} .
$$

The mechanical equation (in the motor referential) used to describe each wheel drive is expressed by

$$
J \frac{d \omega_{m}}{d t}+T_{B}+T_{L}=T_{m} .
$$

The following equation is derived due to the use of a reduction gear:

$$
\left\{\begin{array}{l}
\omega_{\text {Wheel }}=\frac{\omega_{m}}{i} \\
T_{\text {Wheel }}=T_{m} i \eta_{t}
\end{array} .\right.
$$


The load torque in the motor referential is given by

$$
T_{L}=\frac{T_{\text {LWheel }}}{i}=\frac{R}{i} F_{\omega} .
$$

The vehicle global inertia moment in the motor referential is given by

$$
\left\{\begin{array}{l}
J=J_{W}+J_{V} \\
J_{V}=\frac{1}{2} m \frac{R^{2}}{i^{2}}(1-\lambda)
\end{array} .\right.
$$

If the adhesion coefficient of the road surface is high, then $\lambda$ is usually low and can be neglected.

\section{DTC}

The basic idea of the method is to calculate flux and torque instantaneous values only from the stator variables. Flux, torque, and speed are estimated. The input of the motor controller is the reference speed, which is directly applied by the pedal of the vehicle. Control is carried out by hysteresis comparators and a switching logic table selecting the appropriate voltage inverter switching configurations [6]. Fig. 2 gives the global configuration of a DTC scheme and shows how the EV dynamics will be taken into account.

\section{A. Nomenclature}

$V_{s}\left(V_{r}\right) \quad$ Stator (rotor) voltage space vector.

$\lambda_{s}\left(\lambda_{r}\right) \quad$ Stator (rotor) flux space vector.

$R_{s}\left(R_{r}\right) \quad$ Stator (rotor) resistance.

$L_{s}\left(L_{r}\right) \quad$ Stator (rotor) inductance.

$L_{m} \quad$ Magnetizing inductance.

$\sigma \quad$ Total leakage coefficient $\sigma=1-L_{m}^{2} / L_{s} L_{r}$.

$\omega_{r} \quad$ Rotor electric speed.

$\theta_{\lambda s} \quad$ Stator flux angular position.

$p \quad$ Pole-pair number.

\section{B. DTC}

The induction motor model in the stator-fixed $d-q$ reference frame is described by

$$
\left\{\begin{array}{l}
V_{s}=R_{s} i_{s}+\frac{d \lambda_{s}}{d t} \\
0=R_{r} i_{r}+\frac{d \lambda_{s}}{d t}-j \omega_{r} \lambda_{r} \\
\lambda_{s}=L_{s} i_{s}+L_{m} i_{r} \\
\lambda_{r}=L_{m} i_{s}+L_{r} i_{r}
\end{array}\right.
$$

whereas the mechanical equation is given in (8).

The induction motor stator flux can be estimated as follows:

$$
\left\{\begin{array}{l}
\lambda_{\mathrm{ds}}=\int\left(V_{\mathrm{ds}}-R_{s} i_{\mathrm{ds}}\right) d t \\
\lambda_{\mathrm{qs}}=\int\left(V_{\mathrm{qs}}-R_{s} i_{\mathrm{qs}}\right) d t \\
\left|\lambda_{s}\right|=\sqrt{\lambda_{\mathrm{ds}}^{2}+\lambda_{\mathrm{qs}}^{2}} \\
\theta_{\lambda s}=\tan ^{-1}\left(\frac{\lambda_{\mathrm{qs}}}{\lambda_{\mathrm{ds}}}\right)
\end{array} .\right.
$$

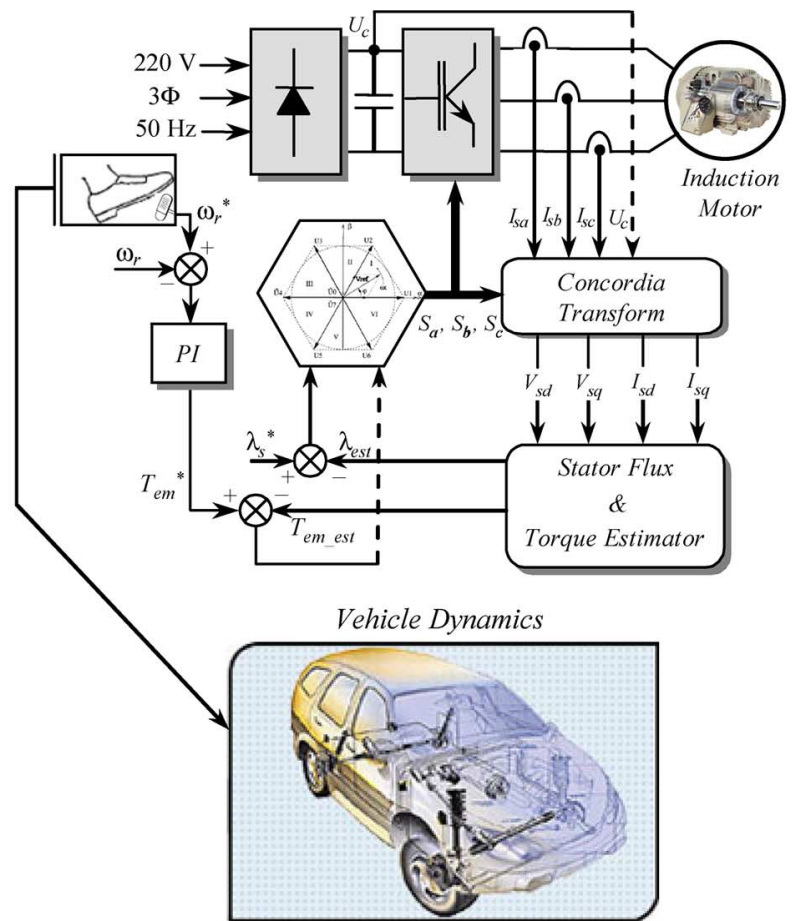

(a)

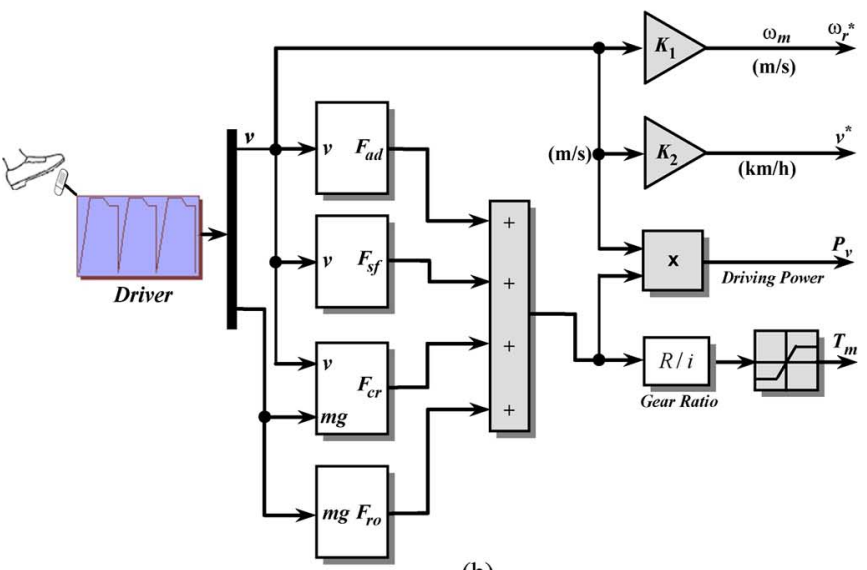

(b)

Fig. 2. DTC general configuration. (a) Vehicle dynamics. (b) EV dynamics.

Then, the electromagnetic torque is estimated using

$$
T_{\mathrm{em}}=\frac{3}{2} \frac{p}{2}\left(\lambda_{\mathrm{ds}} i_{\mathrm{qs}}-\lambda_{\mathrm{qs}} i_{\mathrm{ds}}\right) .
$$

\section{Induction Motor Loss Model}

\section{A. Nomenclature}

$R_{\mathrm{fs}} \quad$ Stator core loss resistance.

$R_{\text {fr }} \quad$ Rotor core loss resistance.

$f_{s} \quad$ Stator frequency.

$k_{h} \quad$ Hysteresis loss coefficient.

$k_{e} \quad$ Eddy current loss coefficient.

$s \quad$ Per-unit slip.

$P_{s} \quad$ Stator copper losses.

$P_{r} \quad$ Rotor copper losses.

$P_{\mathrm{fs}} \quad$ Core losses.

$\omega_{s} \quad$ Stator angular velocity.

$A \quad$ Current ratio $\left(i_{\mathrm{sq}}=A i_{\mathrm{sd}}\right)$. 


\section{B. Loss Model}

The motor losses are calculated from the induction motor equivalent circuit in Fig. 3. The stator and rotor resistances are temperature dependent and thereby dependent on the speed and torque. The magnetizing inductance $L_{m}$ includes saturation. The core loss resistance $R_{\mathrm{fs}}$ depends on air-gap flux, stator frequency, and slip. However, it is more sensitive to frequency variation [9], [10]. It is therefore expressed by

$$
R_{\mathrm{fs}}=k_{h} f_{s}+k_{e} f_{s}^{2} .
$$

This resistance could be neglected at low speed according to the $R_{s}$ value. However, neglecting $R_{\mathrm{fs}}$ results in an error in the slip and rotor flux calculations; therefore, it leads to a torque offset error and a failure in $d-q$ phase current decoupling control. As a result, it degrades the speed response in the high-speed range [9]. The rotor core loss resistance $R_{\mathrm{fr}}$ is given by

$$
R_{\mathrm{fr}}=k_{h} s f_{s}+k_{e}\left(s f_{s}\right)^{2} .
$$

At high speed, the stator flux frequency is almost the same as the speed frequency. The slip frequency is nearly zero, and the rotor core losses could be neglected.

There are four types of losses in an induction motor propelling an EV: 1) copper loss in the stator; 2) core loss in the stator; 3) copper loss in the rotor; and 4) core loss in the rotor. Friction and windage losses are generally neglected.

Using the steady-state induction motor equivalent circuit in Fig. 4 and the power-invariant three-to-two axis transformation, it is observed that the motor loss consists of the following components [13], [14]:

$$
\left\{\begin{aligned}
P_{s} & =R_{s}\left(i_{\mathrm{sd}}^{2}+i_{\mathrm{sq}}^{2}\right) \\
P_{r} & =R_{r}\left(i_{\mathrm{sq}}-\frac{\omega_{s} L_{m}}{R_{\mathrm{fs}}} i_{\mathrm{sd}}\right)^{2} \\
& =R_{r}\left(i_{\mathrm{sq}}^{2}+\left(\omega_{s} L_{m}\right)^{2} \frac{1}{R_{\mathrm{fs}}^{2}} i_{\mathrm{sd}}^{2}-2 \omega_{s} L_{m} \frac{1}{R_{\mathrm{fs}}} i_{\mathrm{sd}} i_{\mathrm{sq}}\right) \\
P_{\mathrm{fs}} & =\left(\omega_{s} L_{m}\right)^{2} \frac{1}{R_{\mathrm{fs}}} i_{\mathrm{sd}}^{2}
\end{aligned}\right.
$$

Rearranging (17), we obtain the following loss components:

$$
\left\{\begin{array}{l}
P_{\mathrm{loss}, d}=\left(\left(\omega_{s} L_{m}\right)^{2} \frac{1}{R_{\mathrm{fs}}}+R_{s}+\left(\omega_{s} L_{m}\right)^{2} \frac{R_{r}}{R_{\mathrm{fs}}^{2}}\right) i_{\mathrm{sd}}^{2} \\
P_{\mathrm{loss}, q}=\left(R_{r}+R_{s}\right) i_{\mathrm{sq}}^{2} \\
P_{\mathrm{loss}, d q}=-2 \omega_{s} L_{m} \frac{R_{r}}{R_{\mathrm{fs}}} i_{\mathrm{sd}} i_{\mathrm{sq}}
\end{array} .\right.
$$

Using the torque expression and the definition of $A$

$$
T_{\mathrm{em}}=p L_{m} i_{\mathrm{sd}} i_{\mathrm{sq}}
$$

the total loss becomes

$$
\begin{array}{r}
P_{\mathrm{loss}}=\frac{T_{\mathrm{em}}}{p L_{m}}\{[ \\
\left.\quad\left[\omega_{s} L_{m}\right)^{2} \frac{1}{R_{\mathrm{fs}}}+R_{s}+\left(\omega_{s} L_{m}\right)^{2} \frac{R_{r}}{R_{\mathrm{fs}}^{2}}\right] \\
\left.\times \frac{1}{A}+\left(R_{r}+R_{s}\right) A-2 \omega_{s} L_{m} \frac{R_{r}}{R_{\mathrm{fs}}}\right\} .
\end{array}
$$

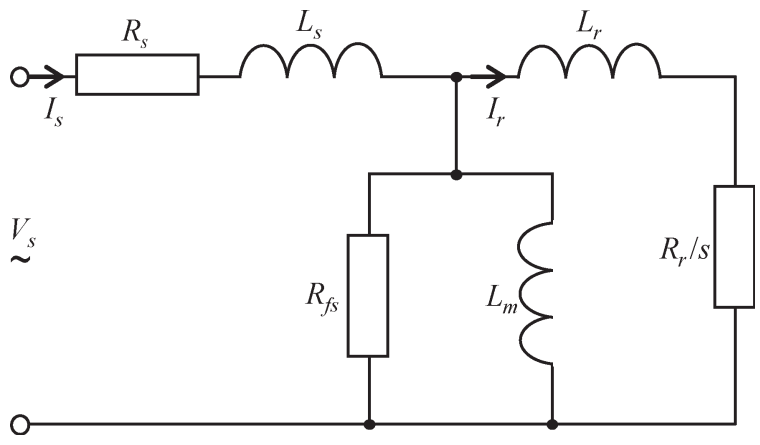

Fig. 3. Induction motor equivalent circuit used to model the losses.

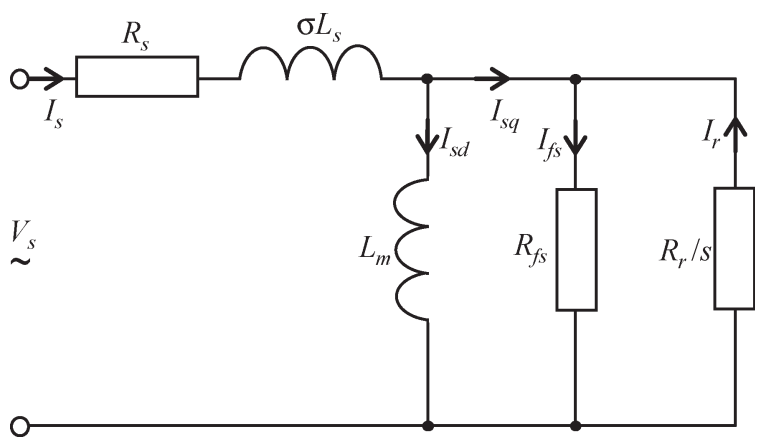

Fig. 4. Induction motor steady-state equivalent circuit.

Differentiating the loss expression (19) with respect to $A$ and assuming that the model parameters are independent of $A$

$$
\left\{\begin{array}{l}
\frac{\partial P_{\text {loss }}}{\partial A}=0 \\
\Rightarrow-\left[\left(\omega_{s} L_{m}\right)^{2} \frac{1}{R_{\mathrm{fs}}}+R_{s}+\left(\omega_{s} L_{m}\right)^{2} \frac{R_{r}}{R_{\mathrm{fs}}^{2}}\right] \frac{1}{A^{2}}+\left(R_{r}+R_{s}\right)=0
\end{array}\right.
$$

will lead to minimum loss and particularly to the following:

$$
P_{\text {loss }, d}=P_{\text {loss }, q} .
$$

The induction motor losses are thus minimal when "direct" losses are equal to "quadrature" ones.

The proposed "model-based" loss-minimization DTC scheme for an EV is shown in Fig. 5. In this case, the model-based control has the advantage over the simple state control [15], [16] in that it can include inverter losses in the calculation. It should be noticed that (20) is solved with a PI controller [17].

It should be kept in mind that model-based loss minimization as adopted here (18), (20) depends on four parameters $\left(R_{s}, R_{r}\right.$, $R_{\mathrm{fs}}$, and $L_{m}$ ) of the induction motor equivalent circuit (Fig. 4). The motor operates below the rated speed at the rated flux and above the rated speed with the optimal flux (weakened). Since the optimal flux is usually lower than the rated one for $\mathrm{EV}$ application, there is no magnetic saturation. Otherwise, magnetic saturation could be neglected on the basis of physical consideration. Indeed, the induction motor temperature increase (thermal effect) due to its operation will perturb and slow down the magnetic saturation process [18]. Therefore, $L_{m}$ could be considered approximately constant. $R_{\mathrm{fs}}$ is assessed using (15). $R_{s}$ and $R_{r}$ are temperature dependent and thereby dependent 


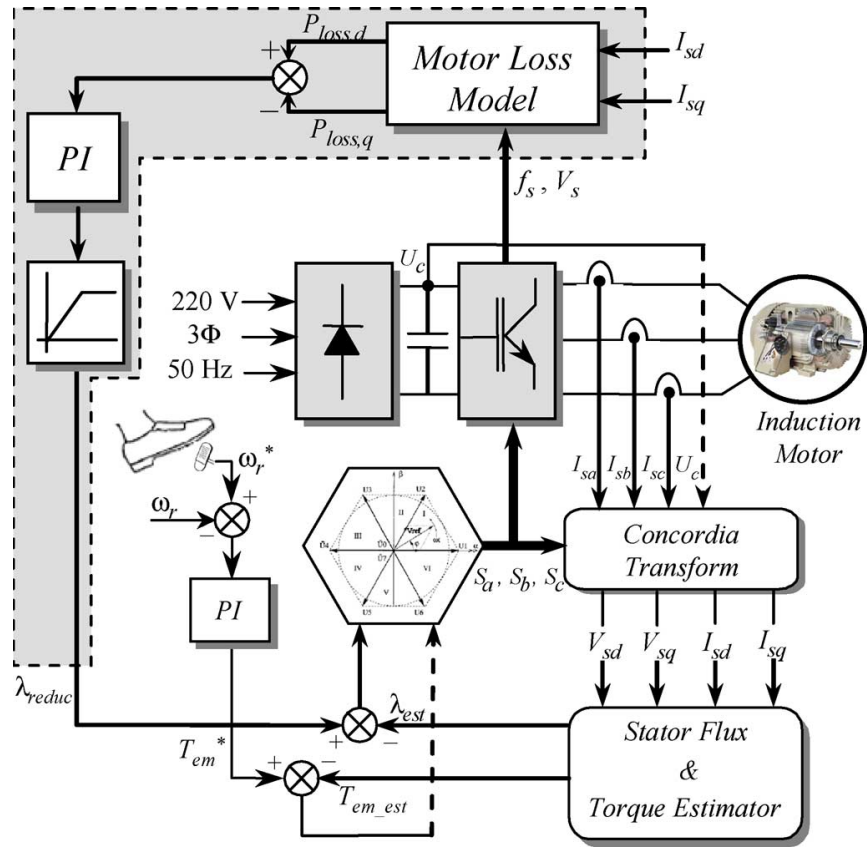

Fig. 5. Scheme for energy-optimal model-based control.

on the speed and torque. They are estimated based on the sensitivity of torque [7].

Loss minimization is performed using search control, which is also called adaptive control or online optimization. In this case, a significant parameter is minimized or maximized by trial and error. In our study, the criterion is minimum motor loss. The principle of the search control is to keep the output power of the motor constant and find the operating point where the input power has a minimum. Measuring the input power and iteratively changing the flux level in small steps until the input power minimum is detected will lead to this minimum. The output power is normally kept constant by keeping the speed constant and assuming a constant load torque [14].

The main advantages of search control is that it does not depend on motor or converter parameters as other control strategies do, and it leads to the true optimal efficiency. An obvious disadvantage is that the speed should be measured. Moreover, the convergence time to reach the optimal efficiency is not less $4 \mathrm{~s}$. Therefore, the method is unusable if the load is changing more often than that. Optimistically, this is not the case. Indeed, in real-time driving, an EV rarely operates in extreme conditions [19].

\section{Simulation Results}

Numerical simulations have been carried out on an EV propelled by a $1.1-\mathrm{kW}$ induction motor drive, the ratings of which are summarized in the Appendix. The magnetizing inductance and the core loss resistance are determined by no-load tests. The rotor resistance and the leakage inductances are determined by locked-rotor tests with stator frequencies from 10 to $50 \mathrm{~Hz}$, and the determined constants are extrapolated down to a few hertz to take into account the skin effect in the rotor.

The objectives of the simulations that were carried out are to assess the efficiency and dynamic performances of the proposed

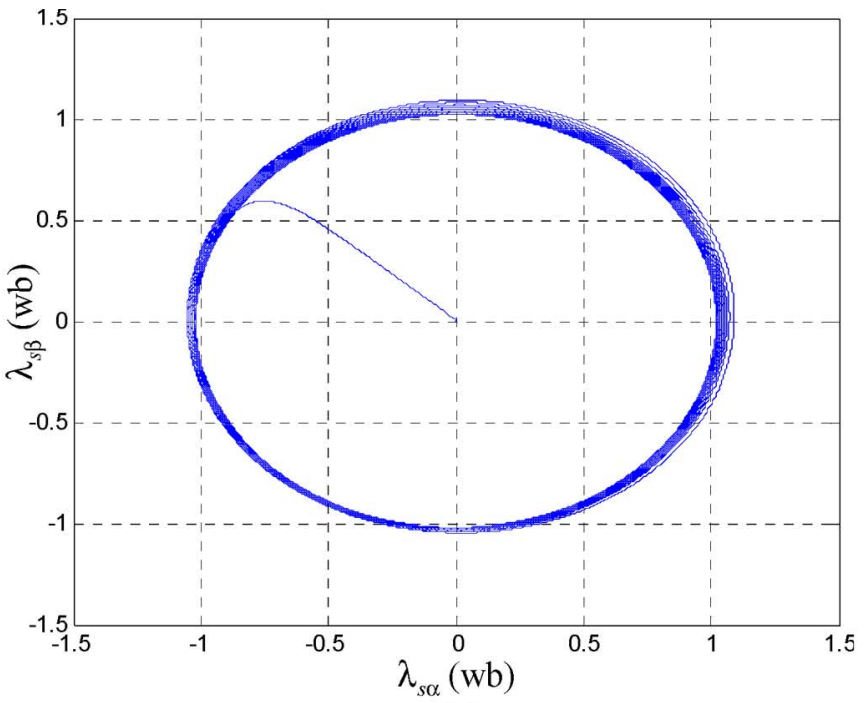

(a)

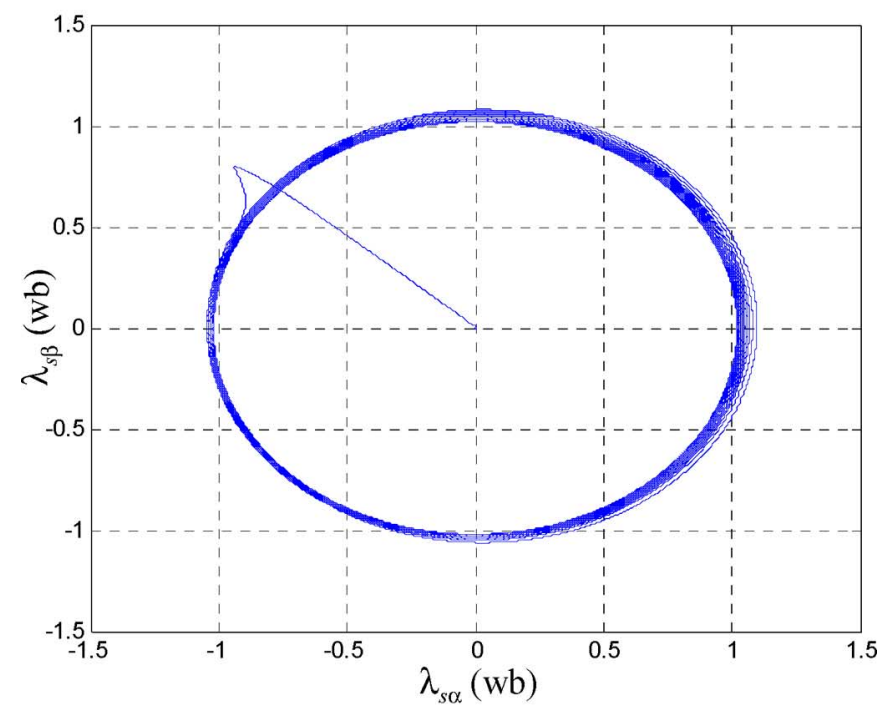

(b)

Fig. 6. Stator flux trajectories. (a) Without optimization. (b) With optimization.

control strategy. The following simulation strategy has been adopted: 1) Nominal flux is applied to the induction motor drive until it reaches its steady state; 2 ) at $t=2.3 \mathrm{~s}$, the lossminimization strategy is engaged.

Fig. 6 illustrates stator flux estimation robustness. Indeed, the flux estimation was not affected by the loss-minimization process apart from a small transient shown in Fig. 6(b).

Fig. 7 shows the performance of the proposed lossminimization strategy. Indeed, in Fig. 7(a), the rapid convergence of the optimization process $\left(P_{\text {loss }, d}=P_{\text {loss }, q}\right)$ in less than $2 \mathrm{~s}$ should be noticed (the stator flux reaches its optimal value). In this case, the efficiency increases from $77 \%$ to $80 \%$ [Fig. 7(b)]. Even if the increase in efficiency is about 3\%, the above results confirm the effectiveness of the proposed loss-minimization strategy. Indeed, no further increase in the efficiency would be expected for this induction motor, mainly due to its rated power. Small induction motors are generally characterized by a relatively small efficiency according to large 


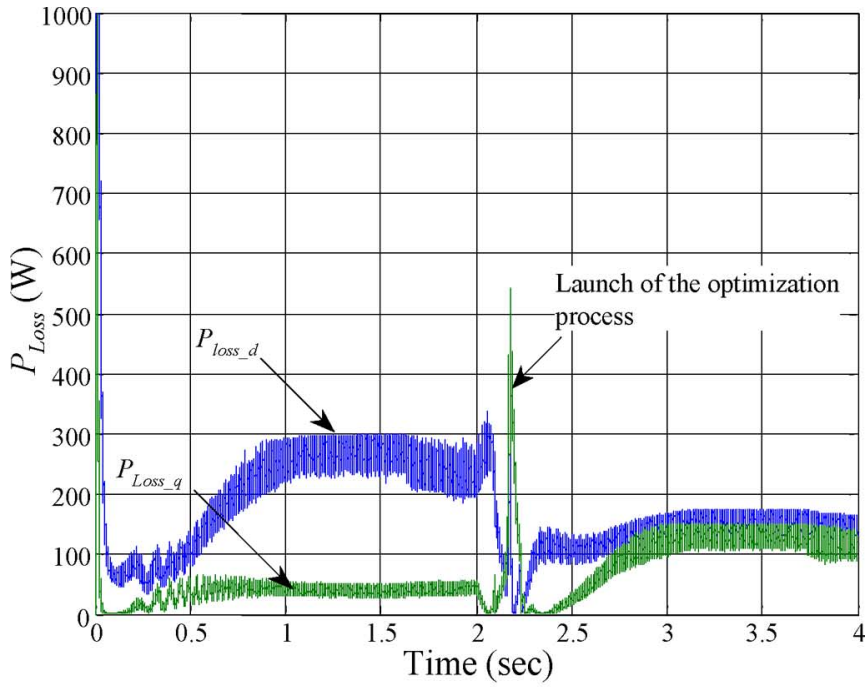

(a)



(b)

Fig. 7. Efficiency and power optimization. (a) $P_{\text {loss }, d}$ and $P_{\text {loss }, q}$ variations. (b) Efficiency.

motors [20]. Therefore, further increase in the efficiency is expected when using larger induction motors [14].

Figs. 8 and 9(a) illustrate the EV dynamics (the speed and the developed torque, respectively) with changes in the acceleration pedal position and a varied road profile (rising and downward portions). It should be noticed that the speed and torque variations are as large as the variations of the accelerator pedal and the road profile. Moreover, Fig. 9 shows that the estimated torque and the developed one are quite similar, which confirms the good torque control of the induction motor.

\section{CONCLUSION}

This paper presented a detailed dynamic model of an EV that is associated with a loss-minimizing DTC induction motor drive strategy. Compared to previous works, the proposed energy optimization strategy is applied to the whole vehicle (by taking into account its aerodynamics) and not to the sole induction motor. This approach was used to directly minimize

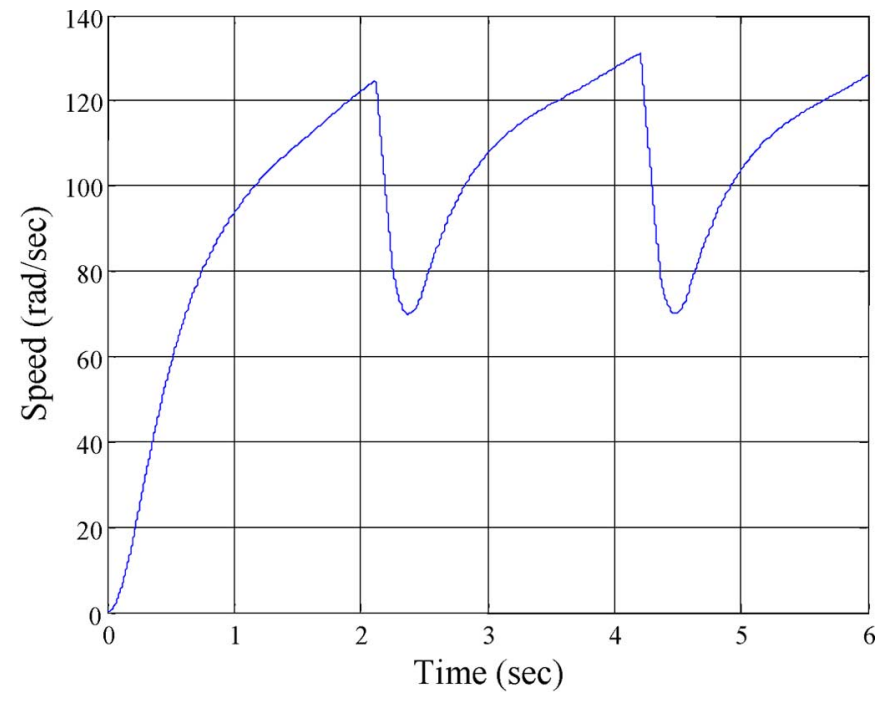

Fig. 8. Speed curve.

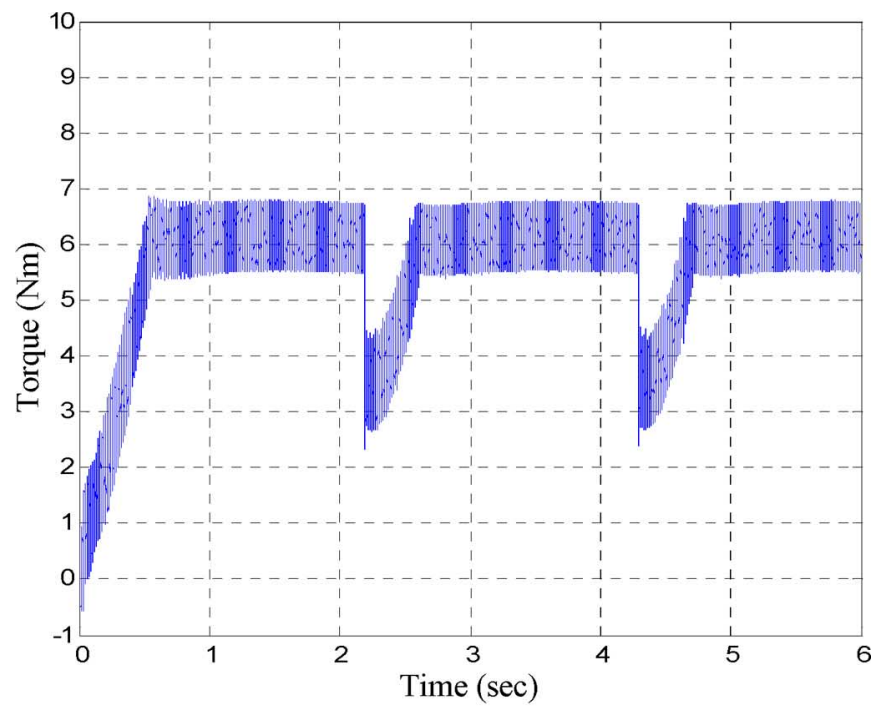

(a)

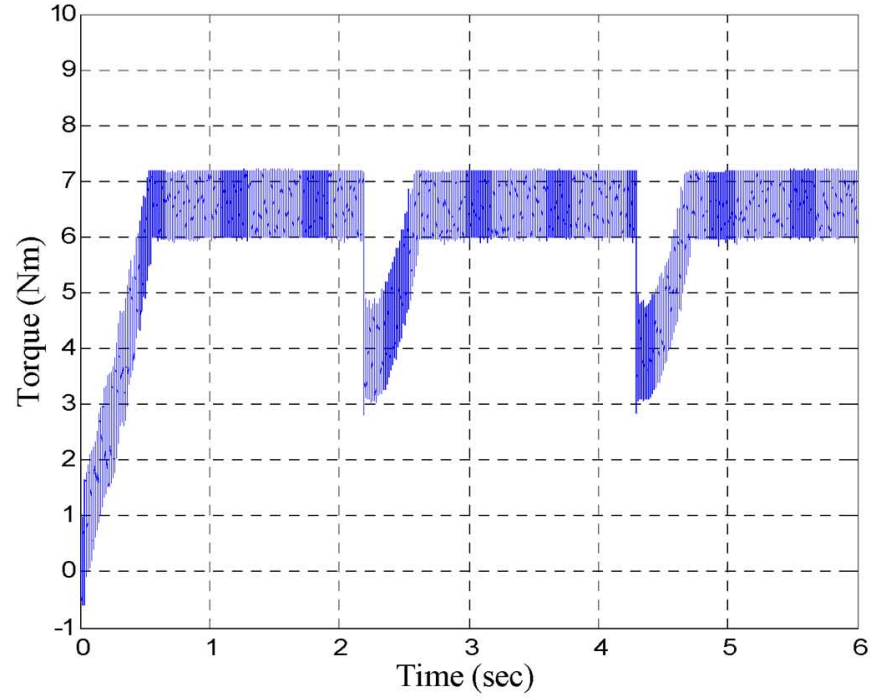

(b)

Fig. 9. Torque curves. (a) Developed torque. (b) Estimated torque. 
the induction motor losses in order to evaluate the optimal magnetizing flux, thus maximizing the efficiency and extending the running distance per battery charge.

Simulations tests that have been carried out on a $1.1-\mathrm{kW}$ EV induction motor drive show that the proposed control approach provides effective loss-minimization control while maintaining a good dynamic response. As small motors are generally characterized by a relatively small efficiency, no further increase in the efficiency would be expected for this induction motor. However, further increase in the efficiency should be achieved when using larger induction motors.

For applications permanently operating in a steady-state mode, applying this approach would produce significant savings. For tolerant systems to slight variations in dynamic response, this application would prove to be very efficient.

\section{APPENDIX}

\section{A. Rated Data of the Simulated Induction Motor}

- $1.1 \mathrm{~kW}, 50 \mathrm{~Hz}, 220 / 380 \mathrm{~V}, 5.9 / 3.4 \mathrm{~A}, 7 \mathrm{~N} \cdot \mathrm{m}, 1500 \mathrm{r} / \mathrm{min}$;

- $R_{s}=8 \Omega, R_{r}=3.1 \Omega, R_{\mathrm{fs}}=86.47 \Omega$;

- $L_{s}=L_{r}=0.47 \mathrm{H}, L_{m}=0.443 \mathrm{H}$;

- $p=2, J=0.06 \mathrm{~kg} \cdot \mathrm{m}^{2}$;

- $\beta=0.042 \mathrm{~N} \cdot \mathrm{m} \cdot \mathrm{s}$.

\section{B. Vehicle Parameters}

- $m=150 \mathrm{~kg}$

- $A_{f}=1 \mathrm{~m}^{2}$

- $R=0.23 \mathrm{~m}$

- $\mu=0.015$

- $C_{w}=0.25$

- $g=9.81 \mathrm{~m} / \mathrm{s}^{2}$

- $k_{A}=0.22, k_{m}=1.08$

- $\xi=0.23 \mathrm{~kg} / \mathrm{m}^{2}$;

- $i=5$.

\section{REFERENCES}

[1] C. C. Chan, "The state of the art of electric and hybrid vehicles," Proc. IEEE, vol. 90, no. 2, pp. 247-275, Feb. 2002.

[2] M. E. H. Benbouzid et al., "Electric motor drive selection issues for HEV propulsion systems: A comparative study," IEEE Trans. Veh. Technol., vol. 55, no. 6, pp. 1756-1764, Nov. 2006.

[3] D. O. Neacsu et al., "Comparative analysis of torque-controlled IM drives with applications in electric and hybrid vehicles vehicle," IEEE Trans. Power Electron., vol. 16, no. 2, pp. 240-247, Mar. 2001.

[4] G. S. Buja et al., "Direct torque control of PWM inverter-fed ac motors-A survey," IEEE Trans. Ind. Electron., vol. 51, no. 4, pp. 744-757, Aug. 2004.

[5] C. Lascu et al., "A sensorless hybrid DTC drive for high-volume low-cost applications," IEEE Trans. Ind. Electron., vol. 51, no. 5, pp. 1048-1055, Oct. 2004

[6] J. Faiz et al., "Sensorless direct torque control of induction motors used in electric vehicle," IEEE Trans. Energy Convers., vol. 18, no. 1, pp. 1-10, Mar. 2003.

[7] _ _ "Different techniques for real time estimation of an induction motor rotor resistance in sensorless direct torque control for electric vehicle," IEEE Trans. Energy Convers., vol. 16, no. 1, pp. 104-109, Mar. 2001.

[8] M. Ehsani et al., "Propulsion system design of electric and hybrid vehicles," IEEE Trans. Ind. Electron., vol. 45, no. 1, pp. 19-27, Feb. 1997.

[9] J. Jung et al., "A vector control schemes for EV induction motors with a series iron loss model," IEEE Trans. Ind. Electron., vol. 45, no. 4, pp. 617-624, Aug. 1998.
[10] S. Lim et al., "Loss-minimizing control scheme for induction motor," Proc. Inst. Electr. Eng.—Electr. Power Appl., vol. 151, no. 4, pp. 385-397, Jul. 2004.

[11] B. Szadkowski et al., "A study of energy requirements for electric and hybrid vehicles in cities," in Proc. Int. Conf. Clean, Efficient and Safe Urban Trans., Gdansk, Poland, Jun. 4-6, 2003, pp. 1-8.

[12] I. Husain et al., "Design, modeling and simulation of an electric vehicle system," Paper 1999-01-1149, SAE Technical Paper Series.

[13] F. Abrahamsen et al., "Efficiency-optimized control of mediumsize induction motor drives," IEEE Trans. Ind. Appl., vol. 37, no. 6 , pp. 1761-1767, Nov./Dec. 2001.

[14] _ , "On the energy optimized control of standard and high-efficiency induction motors in CT and HVAC applications," IEEE Trans. Ind. Appl., vol. 34, no. 4, pp. 822-883, Jul./Aug. 1998.

[15] D. Diallo et al., "A fuzzy technique for loss minimization in scalarcontrolled induction motor," Electr. Power Compon. Syst., vol. 30, no. 6 , pp. 625-635, Jun. 2002.

[16] M. E. H. Benbouzid et al., "An efficiency-optimization controller for induction motor drives," IEEE Power Eng. Rev., vol. 18, no. 5, pp. 43-45, May 1998.

[17] K. S. Rasmussen et al., "Model based energy optimizer for vector controlled induction motor drives," in Proc. Eur. Power Electron. Conf., Trondheim, Norway, Sep. 1997, vol. 3, pp. 711-716.

[18] M. E. H. Benbouzid et al., "Induction motors direct field oriented control with robust on-line tuning of rotor resistance," IEEE Trans. Energy Convers., vol. 14, no. 4, pp. 1038-1042, Dec. 1999.

[19] Z. Rahman et al., "An investigation of electric motor drive characteristics for EV and HEV propulsion systems," Paper 2000-01-3062, SAE Technical Paper Series.

[20] A. H. Bonnett, "An update on ac induction motor efficiency," IEEE Trans. Ind. Appl., vol. 30, no. 5, pp. 1362-1372, Sep./Oct. 1994.

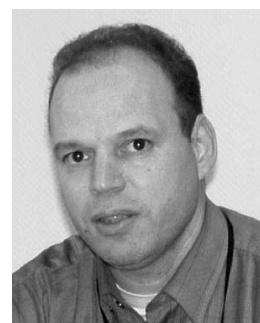

Abdelhakim Haddoun was born in Constantine, Algeria, in 1967. He received the B.Sc. and M.Sc. degrees in electrical engineering from the University of Batna, Batna, Algeria, in 1993 and 1999, respectively. He is currently working toward the $\mathrm{Ph} . \mathrm{D}$. degree in electric vehicle control and power management from the University of Batna.

In 2000, he joined the Department of Electrical Engineering, University of Oum El Bouaghi, Oum El Bouaghi, Algeria, as a Teaching Assistant.

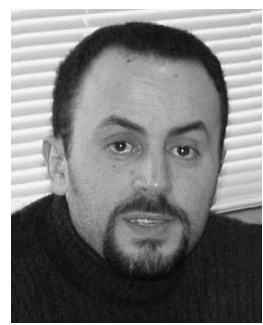

Mohamed El Hachemi Benbouzid (S'92-M'95SM'98) was born in Batna, Algeria, in 1968. He received the B.Sc. degree in electrical engineering from the University of Batna, in 1990, the M.Sc. and $\mathrm{Ph} . \mathrm{D}$. degrees in electrical and computer engineering from the National Polytechnic Institute of Grenoble, Grenoble, France, in 1991 and 1994, respectively, and the Habilitation à Diriger des Recherches degree from the University of Picardie "Jules Verne," Amiens, France, in 2000.

After receiving the Ph.D. degree, he joined the Professional Institute of Amiens, University of Picardie "Jules Verne," where he was an Associate Professor of electrical and computer engineering. In September 2004, he joined the University Institute of Technology (IUT) of Brest, University of Western Brittany, Brest, France, as a Professor of electrical engineering. His main research interests and experience include analysis, design, and control of electric machines, variable-speed drives for traction and propulsion applications, and fault diagnosis of electric machines.

Prof. Benbouzid is a Senior Member of the IEEE Power Engineering, Industrial Electronics, Industry Applications, Power Electronics, and Vehicular Technology Societies. He is an Associate Editor of the IEEE TRANSACTIONS ON ENERGY CONVERSION, the IEEE TRANSACTIONS ON INDUSTRIAL ElECtronics, the IEEE TRANSACTIONS ON Vehicular TeChNOLOGY, and the IEEE/ASME TRANSACTIONS ON MECHATRONICS. 


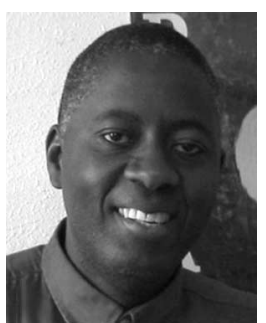

Demba Diallo (M'99-SM'05) was born in Dakar, Senegal, in 1966. He received the M.Sc. and Ph.D. degrees in electrical and computer engineering from the National Polytechnic Institute of Grenoble, Grenoble, France, in 1990 and 1993, respectively, and the Habilitation à Diriger des Recherches degree from the University of Paris VI, Gif-Sur-Yvette, France, in 2005.

From 1994 to 1999, he was a Research Engineer with the Laboratoire d'Electrotechnique de Grenoble, where he worked on electrical drives and active filters (hardware and software). In 1999, he joined the University of Picardie "Jules Verne," Amiens, France, as an Associate Professor of electrical engineering. In September 2004, he joined the University Institute of Technology (IUT) of Cachan, University of Paris VI \& XI, as an Associate Professor of electrical engineering. He is currently with the Laboratoire de Génie Electrique de Paris, Unite Mixte de Recherche 8507, Centre National de la Recherche Scientifique, University of Paris VI \& XI. His current area of research includes advanced control techniques and diagnosis in the field of ac drives.

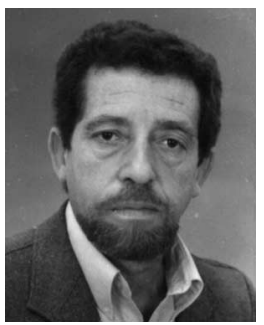

Rachid Abdessemed was born in Batna, Algeria, in 1951. He received the M.Sc. and Ph.D. degrees in electrical engineering from Kiev Polytechnic Institute, Kiev, Ukraine, in 1978 and 1982, respectively.

He has been working for more than 18 years with the Department of Electrical Engineering, University of Batna, as a Professor. Currently, he is the Director of the Electrical Engineering Laboratory. His current area of research includes design and control of induction machines, reliability, magnetic bearings, and renewable energy.

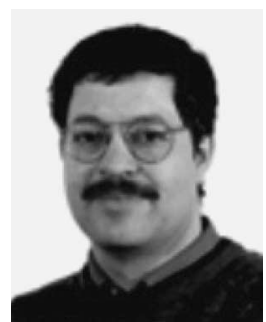

Jamel Ghouili was born in Ghardimaou, Tunisia, in 1962. He received the B.Sc., M.Sc., and Ph.D. degrees from the University of Québec at TroisRivières, Trois-Rivières, QC, Canada, in 1986, 1998, and 2004, respectively.

$\mathrm{He}$ is currently a Professor with the University of Moncton, Moncton, NB, Canada, where he has been responsible for teaching and research program in power electronics and drives since 2000 . Early in his career, he served as a Professor with the Ecole Polytechnique de Masuku, Masuku, Gabon. His main research interests include power converters, ac drives, DSP and FPGA control, sensorless control, EV/HEV drives, and fuzzy logic and neural network applications in power electronics and drives.

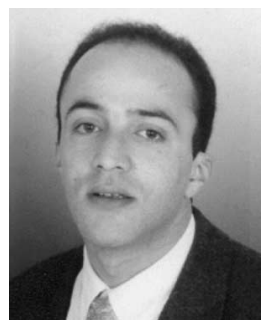

Kamel Srairi was born in Batna, Algeria, in 1967. $\mathrm{He}$ received the B.Sc. degree in electrical engineering from the University of Batna, in 1991, the M.Sc. degree in electrical and computer engineering from the National Polytechnic Institute of Grenoble, Grenoble, France, in 1992, and the Ph.D. degree in electrical and computer engineering from the University of Nantes, Nantes, France, in 1996.

After receiving the $\mathrm{Ph} . \mathrm{D}$. degree, he joined the Department of Electrical Engineering, University of Biskra, Biskra, Algeria, where he is an Associate Professor. His main research interests include analysis, design, and control of electric machines. 